\title{
STUDY OF PANEL OF DIAGNOSTIC CARDIAC MARKERS FOR ACUTE MYOCARDIAL INFARCTION
}

\author{
ANOOP KUMAR ${ }^{1}$, PREETI SHARMA ${ }^{1}$, PRADEEP KUMAR ${ }^{1}$, ASHOK KUMAR ${ }^{2}$
}

${ }^{1}$ Department of Biochemistry, Santosh Medical College and Hospital, Ghaziabad, Uttar Pradesh, India, ${ }^{2}$ Department of Medicine, Santosh Medical College and Hospital, Ghaziabad. Email: prcdri2003@yahoo.co.in

Received: 16 September 2018, Revised and Accepted: 16 November 2018

\section{ABSTRACT}

Objectives: The aim of this study is to estimate the level of creatine kinase-myocardial band (CK-MB), C-reactive protein (CRP), and lactate dehydrogenase (LDH) biomarker in myocardial infarction (MI) (troponin T-positive) and compare with normal healthy individuals (Troponin-T [TnT] negative).

Methods: A cross-sectional study on 172 patients involving 100 patients with nondiabetic MI and 72 apparently healthy controls with no history of diabetes and/or MI was done from December 2017 to May 2018. The diagnosis of MI was established with electrocardiogram findings and TnT estimation. Blood samples were gathered and processed for the estimation of CK-MB, LDH, and CRP.

Results: The mean age of the cases was $62.15 \pm 7.75$ years and in the controls was $61.49 \pm 8.35$ years ( $p=0.592$ ). The mean value of CK-MB, LDH, and CRP in the TnT positive group was $111.94 \pm 29.59 \mathrm{IU} / \mathrm{L}, 564.43 \pm 110.99 \mathrm{IU} / \mathrm{L}$, and $15.69 \pm 4.04 \mathrm{mg} / \mathrm{L}$, whereas in the TnT negative group was $16.36 \pm 3.77 \mathrm{IU} / \mathrm{L}, 223.68 \pm 36.23 \mathrm{IU} / \mathrm{L}$, and $6.08 \pm 2.02 \mathrm{mg} / \mathrm{L}$, respectively $(\mathrm{p}<0.0001)$. CK-MB was deranged in $100 \%$ of TnT positive group, and in only $2.78 \%$ in TnT negative group ( $\mathrm{p}<0.0001$ ). LDH was deranged in $100 \%$ TnT positive group, and in $16.67 \%$ in TnT negative group (p<0.0001). CRP was deranged in $4 \%$ TnT positive group, and in $0 \%$ in TnT negative group ( $\mathrm{p}=0.141)$.

Conclusion: This study indicated that CK-MB and LDH are sensitive cardiac markers for the diagnosis of MI.

Keywords: Myocardial, Troponin, Dehydrogenase.

(C) 2019 The Authors. Published by Innovare Academic Sciences Pvt Ltd. This is an open access article under the CC BY license (http://creativecommons. org/licenses/by/4. 0/) DOI: http://dx.doi.org/10.22159/ajpcr.2019.v12i3.29560

\section{INTRODUCTION}

Myocardial infarction (MI) may be described as the death of the heart muscles. Coronary artery disease (CAD) leads to blood flow obstruction to the heart, and the results form a spectrum of diseases, acute coronary syndrome and a consequence of which leads to decrease in the blood flow to the heart [1].

CAD is one of the main causes of death and disability in developed countries [2]. Although the mortality for this condition has gradually declined over the past decades in western countries, it still causes about one-third of all deaths in people older than 35 years [3]. The diagnosis of acute MI (AMI) established by the World Health Organization, requires at least two of the following criteria: A history of chest pain, evolutionary changes on the electrocardiogram (ECG), and elevation of serial cardiac enzymes. If ECG fails to demonstrate an AMI, the cardiac markers must be used [4].

Various cardiac markers-creatine kinase (CK); lactate dehydrogenase (LDH); Cardiac Troponin-I and Troponin-T (TnT); myoglobin; cholesterol; triglycerides; low-density lipoprotein; high-density lipoprotein, C-reactive protein (CRP), and aspartate aminotransferase (AST) have been proposed till date [4]. The assessment of the myocardial injury varies dramatically with the detection of AST, LDH, creatine kinase (CK), CK isoenzymes (CKMB), and troponin (T) which add prognostic information regarding acute short-term or chronic longterm risk and the severity of the injury [5]

Each individual marker carries significance in different scenarios. Serum LDH is a known pathologic marker for myocardial ischemia [6], but it can be falsely elevated with strenuous physical activity. CK-MB rises in the serum at 4-9 h after the onset of chest pain, peaks at $24 \mathrm{~h}$ and returns to baseline values at 48-72 h. CK-MB has an advantage over troponins because of the early clearance that helps to detect reinfarction [7]. Anoop CRP is an acute phase protein that rises with an inflammatory stimulus. CRP is increased in patients with unstable angina; however, owing to the lack of sensitivity and specificity, it cannot be employed as a diagnostic marker alone. As a prognostic indicator, high CRP levels have also been linked to poor outcome [8].

Thus, this study was conducted to assess the most sensitive cardiac marker out of all these three cardiac markers for the early diagnosis of AMI.

\section{MATERIALS AND METHODS}

A cross-sectional study was conducted in the department of biochemistry in a tertiary care hospital. A total of 172 patients were included in this study, divided into two groups. Group I (Cases) - consisted of 100 diagnosed cases of nondiabetic MI admitted to emergency and intensive care units of the Santosh Medical college Hospital and RC Ghaziabad. Group II (controls) consisted of 72 healthy controls with no history of diabetes and/or MI. Informed consent was obtained from patients. Information extraction forms were utilized to collect data from patient files.

All patients $>35$ years (males and females) of confirmed nondiabetic MI based on ECG findings and cardiac enzymes (TnT/CPK-MB) were included in the study. Patients with diabetes mellitus having MI, recent history of surgery and trauma within the preceding 2 months, renal insufficiency (serum creatinine $>1.5 \mathrm{mg} / \mathrm{dl}$ ), patients with cerebrovascular accidents or previous history of cerebrovascular accidents, patients having evidence of infections, inflammatory disease, malignancy, patient taking drugs such as Vitamin B-complex or folic 
acid, hormone replacement therapy, and those who were not willing to participate were excluded from the study. The initial evaluation of patients with MI consisted of history, physical examination, ECG changes, and laboratory investigation (Troponin T). The blood samples were collected from all the cases and controls and were immediately analyzed for biochemical parameters.

Under all aseptic precautions, about $5 \mathrm{ml}$ of venous blood samples were collected by clean venepuncture in a sterile plain and ethylenediaminetetraacetic acid vial. Blood samples were allowed to coagulate after which they were centrifuged at $3000 \mathrm{rpm}$ for $5 \mathrm{~min}$ to obtain serum. The separated clear serum was transferred into sterile bottles and used for the enzyme assay. When not used immediately, they were kept at $-20^{\circ} \mathrm{C}$ and later used within 5 days.

Measurement of Troponin $\mathrm{T}$ was done qualitatively by rapid test kit method manufacturing by Roche Diagnostics International Ltd., CH-6343 Rotkreuz, Switzerland. Measurement of creatine kinase-myocardial band (CK-MB) and LDH was done following a method that has been carried out in accordance with the International Federation of Clinical Chemistry (IFCC) protocol. The commercial kit produced by TransAsia Biomedical Ltd., (H.P.) was used. Measurement of CRP was done by endpoint method. The commercial kit produced by Erba Lachema s.r.o., was used.

\section{Statistical analysis}

Categorical variables were presented in number and percentage (\%), and continuous variables were presented as mean \pm standard deviation

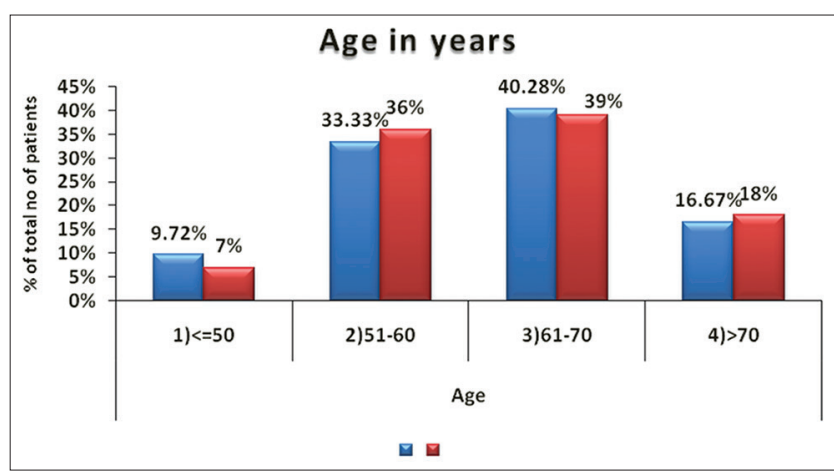

Fig. 1: Age distribution

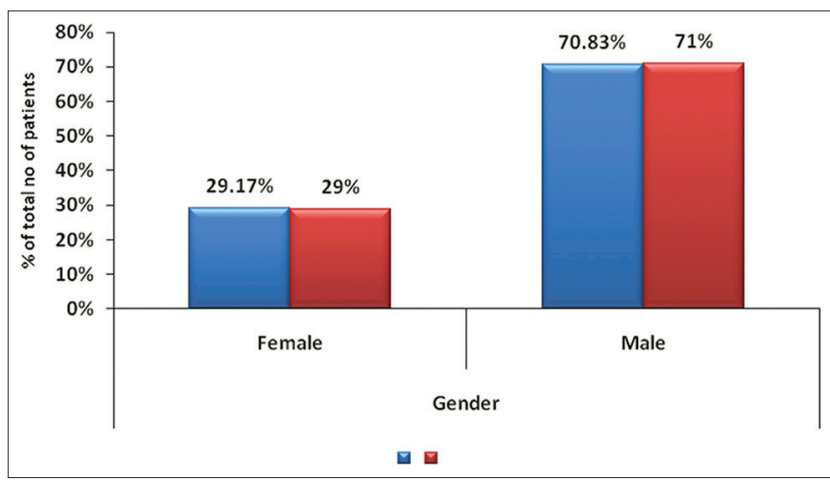

Fig. 2: Gender distribution and median. Normality of data was tested by the Kolmogorov-Smirnov test. If normality was rejected, then the nonparametric test was used.

Statistical tests were applied as follows:

1. Quantitative variables were compared using the independent t-test/Mann-Whitney test (when the data sets were not normally distributed) between the two groups

2. Qualitative variables were correlated using the Chi-Square test/ Fisher's exact test

3. Spearman rank correlation coefficient was used to measure the association of various parameters with each other

4. Univariate logistic regression was used to evaluate significant risk factors for Troponin T positive.

A value of $p<0.05$ was considered as statistically significant.

Data were entered into MS Excel spreadsheet and analysis was performed using the Statistical Package for Social Sciences version 21.0.

\section{RESULTS}

In the present study, a total of 100 Troponin $\mathrm{T}$ positive cases and 72 Troponin $\mathrm{T}$ negative as controls were examined. Troponin $\mathrm{T}$ positive group had $39 \%$ of patients within the age group of $61-70,36 \%$ between 51 and $60,18 \%$ were $>70$ years, and $7 \%$ were $\leq 50$ years. In Troponin $\mathrm{T}$ negative group, $40.28 \%$ were between 61 and 70 years, $33.33 \%$ were between 51 and 60 years, $16.67 \%$ were $>70$ years of age, and $9.72 \%$ were $\leq 50$ years (Table 1 and Fig. 1). The mean age in the cases were $62.15 \pm 7.75$ years and in the controls was $61.49 \pm 8.35$ years. There was not any statistical difference between the two groups $(\mathrm{p}=0.592)$. It has been shown in Table $1 \mathrm{a}$.

In the present study, Troponin T positive group had 29\% of females and $71 \%$ of males, whereas the control group had $29.17 \%$ of females and $70.83 \%$ of males. It has been shown in Table 2 and Fig. 2 .

The mean value of CK-MB, LDH, and CRP in the Troponin T positive group was $111.94 \pm 29.59 \mathrm{IU} / \mathrm{L}, 564.43 \pm 110.99 \mathrm{IU} / \mathrm{L}$ and $15.69 \pm 4.04 \mathrm{mg} / \mathrm{L}$, whereas in the Troponin $\mathrm{T}$ negative group it was $16.36 \pm 3.77 \mathrm{IU} / \mathrm{L}$, $223.68 \pm 36.23 \mathrm{IU} / \mathrm{L}$, and $6.08 \pm 2.02 \mathrm{mg} / \mathrm{L}$, respectively $(\mathrm{p}<0.0001)$ (Table 3).

In the present study, CK MB was deranged in 100\% Troponin T positive group, and in only $2.78 \%$ in Troponin $\mathrm{T}$ negative group. The difference was statistically significant $(\mathrm{p}<0.0001)$ as shown in Table 4 .

LDH was deranged in 100\% Troponin T positive group, and in only $16.67 \%$ in Troponin $\mathrm{T}$ negative group. The difference was statistically significant $(\mathrm{p}<0.0001)$ as shown in Table 5.

CRP was deranged in only $4 \%$ Troponin $\mathrm{T}$ positive group, and in $0 \%$ in Troponin T negative group. It was normal in the rest of the patients. The difference was not statistically significant $(p=0.141)$ as shown in Table 6.

\section{DISCUSSION}

The ongoing battle to reduce the incidence of cardiovascular disease has led to the discovery of numerous clinical markers. In this study, TnT was taken as a standard positive marker for AMI and all correlations of the cardiac biomarkers were done on the basis of the groups defined

Table 1: Age distribution

\begin{tabular}{|c|c|c|c|c|}
\hline Age group (years) & Troponin-T negative (n=72), $n$ (\%) & Troponin-T positive $(n=100), n(\%)$ & Total, n (\%) & $\mathbf{p}$ \\
\hline$\leq 50$ & $7(9.72)$ & $7(7.00)$ & $14(8.14)$ & 0.913 \\
\hline $51-60$ & $24(33.33)$ & $36(36.00)$ & $60(34.88)$ & \\
\hline $61-70$ & $29(40.28)$ & 39 (39.00) & 68 (39.53) & \\
\hline$>70$ & $12(16.67)$ & $18(18.00)$ & $30(17.44)$ & \\
\hline
\end{tabular}


Table 1a: Mean of age distribution

\begin{tabular}{lll}
\hline Age & Troponin-T negative $(\mathbf{n = 7 2 )}$ & Troponin-T positive (n=100) \\
\hline Mean \pm SD & $61.49 \pm 8.35$ & $62.15 \pm 7.75$ \\
Median (range) & $61.5(39-76)$ & $62(42-76)$ \\
IQR & $56-68$ & $56.500-68$ \\
\hline
\end{tabular}

IQR: Inter quartile range, SD: Standard deviation

Table 2: Gender distribution

\begin{tabular}{llll}
\hline Gender distribution & Troponin-T negative (n=72), n (\%) & Troponin-T positive (n=100), n (\%) & Total, n (\%) \\
\hline Female & $21(29.17)$ & $29(29.00)$ & $50(29.07)$ \\
Male & $51(70.83)$ & $71(71.00)$ & $122(70.93)$ \\
\hline
\end{tabular}

Table 3: Mean distribution of cardiac marker

\begin{tabular}{llll}
\hline $\begin{array}{l}\text { Cardiac } \\
\text { markers }\end{array}$ & $\begin{array}{l}\text { Troponin } \mathbf{T} \\
\text { negative }(\mathbf{n}=\mathbf{7 2})\end{array}$ & $\begin{array}{l}\text { Troponin-T } \\
\text { positive }(\mathbf{n = 1 0 0})\end{array}$ & $\mathbf{p}$ \\
\hline CK MB (IU/l) & $16.36 \pm 3.77$ & $111.94 \pm 29.59$ & $<0.0001$ \\
LDH (IU/l) & $223.68 \pm 36.23$ & $564.43 \pm 110.99$ & \\
CRP (mg/l) & $6.08 \pm 2.02$ & $15.69 \pm 4.04$ & \\
\hline
\end{tabular}

LDH: Lactate dehydrogenase, CRP: C-reactive protein, CK MB: Creatine kinase muscle-brain

as Troponin $\mathrm{T}$ positive (cases) and TnT negative (controls). It has been shown that TnT serves as one of the most sensitive markers of myocardial injury. In Shah and Haridas study, it was seen that cardiac TnT was twenty times higher among patients than normal controls [9].

Although both cardiac and skeletal muscles contain TnT like other cardiac markers, the amino acid sequence of the protein in the two types of muscles differs, thus making it possible to raise antisera against cardiac-specific TnT and detect it more efficiently. The high specificity and sensitivity of cardiac TnT in diagnosing and monitoring AMI, the undetectable values of cardiac troponin $\mathrm{T}$ in healthy individuals, has made its measurement a powerful tool in the diagnosis of AMI [9].

In this study, the mean age of the cases was $62.15 \pm 7.75$ years and the controls was $61.49 \pm 8.35$ years. There was no statistically significant difference between the ages of the two groups ( $\mathrm{p}>0.05)$. TnT positive group had $29 \%$ of females and $71 \%$ of males and the control group had $29.17 \%$ of females and $70.83 \%$ of males, which was comparable ( $p>0.05)$. In a comparable study, the mean age was $56.3 \pm 13.2$ years, $145(72.5 \%)$ were male and $55(27.5 \%)$ female [10]. In a study by Sorathia et al., the mean age of the 30 cases was $48.5 \pm 10.3$ years and the 20 controls were $44.5 \pm 12.8$ years which was comparable [11]. In another study by Singh and Manda, in 80 STEMI patients, mean age was $53.5 \pm 1.34$ years and gender distribution were $81.25 \%$ of males and $18.75 \%$ of females [12]

Among the various cardiac markers studied, CK-MB is one of the most important myocardial markers, and it is an established marker in confirmation of AMI. In AMI, the plasma concentration of CK-MB increases within 4-9 h of onset of chest pain, the peak is attained within 9-30 $\mathrm{h}$ and return to baseline levels after 48-72 h [7].

In the present study, the mean value of CK-MB in the Troponin $\mathrm{T}$ positive group was $111.94 \pm 29.59 \mathrm{IU} / \mathrm{l}$ and the Troponin T negative group was $16.36 \pm 3.77 \mathrm{IU} / \mathrm{l}$. The difference was statistically significant $(\mathrm{p}<0.0001)$ CK-MB was deranged in $100 \%$ TnT positive group, and in only $2.78 \%$ in TnT negative group. The difference was statistically significant $(\mathrm{p}<0.0001)$. Shah and Haridas [9] showed that CK-MB values were better than CK as the mean values of CK-MB after $6 \mathrm{~h}$ of chest pain was $98.8 \pm 72.7$ and was $8.5 \pm 14.9$ among controls in TnT negative patients which corroborated with the present study. Aseri et al. [13] showed a significant difference between CK-MB values of STEMI and NSTEMI patients $(p=0.034)$, thereby confirming the relevance of CK-MB as a cardiac marker. Shah [14] also assessed various cardiac markers in 50 AMI cases and 20 controls. Mean values of Total CPK were $148 \pm 279.1$ in control and $648 \pm 806.7$ in MI cases. CPK-MB was $20.9 \pm 9.58$ in control and $89.4 \pm 118.07$ in MI cases. The difference was statistically significant $(\mathrm{p}=0.002)$, and it was comparable to our study.

Serum LDH is a known pathologic marker for a diversity of diseases, including myocardial ischemia. Its activity rises in serum within 12-24 h after AMI, reaches to peak level after 48-72 h after AMI and reverts to normal in 10-14 days. That's why considered as a late marker [6].

In the present study, LDH was deranged in $100 \%$ TnT positive group, and in only $16.67 \%$ in TnT negative group. The difference was statistically significant $(\mathrm{p}<0.0001)$. The mean value of LDH in the Troponin T positive group was $564.43 \pm 110.99$ and the Troponin $\mathrm{T}$ negative group was $223.68 \pm 36.23$. The difference was statistically significant $(p<0.0001)$. Shah [14] results were slightly higher than ours for LDH values. The mean value of LDH was $510 \pm 199.4$ in control and $836.6 \pm 553.1$ in MI cases $(p=0.002)$. Aseri et al. [13] showed a significant difference between the LDH values of STEMI and NSTEMI patients. $(p=0.047)$, thereby confirming the relevance of LDH as a cardiac marker.

Inflammation plays a major role in the pathogenesis of atherosclerosis. The chronic inflammatory process develops to an acute clinical event by the induction of plaque rupture and therefore, causes acute coronary syndromes [13].

In the present study, the mean values of CRP in the Troponin T positive group were $15.69 \pm 4.04$ and the Troponin $\mathrm{T}$ negative group was $6.08 \pm 2.02$. The difference was statistically significant $(\mathrm{p}<0.0001)$. Aseri et al. [13] showed a significant difference between hsCRP values of STEMI and NSTEMI patients. ( $p=0.023$ ) This observational study reports that the inflammatory markers measurement in ACS, before the tissue necrosis, is significantly related to classical cardiac enzyme markers and may be of prognostic significance. CRP has been investigated mostly in acute coronary syndromes as a marker of proinflammatory state and plaque instability. Few studies also concluded that there was no significant correlation between hs-CRP levels and Gensini score index and no relationship between hs-CRP levels and the presence and severity of CAD in patients with stable angina [13]. All the three cardiac markers showed a significant association with AMI and thus shall form an important component of the test panel for early diagnosis of MI. The values should be interpreted carefully and individually as each of them holds a separate significance.

The study results should be interpreted within the context of several limitations. First, the study design prevents inference of causal relationships among variables. Although there has been a lot of research on these markers, their relevance and application to different geography and ethnicity remain doubtful. Finally, study on ejection fraction was not done on this study which forms a major component in the assessment of AMI. 
Table 4: Creatine kinase muscle-brain derangement

\begin{tabular}{lllll}
\hline CK MB (IU/L) & Troponin-T negative $(\mathbf{n}=\mathbf{7 2}), \mathbf{n}(\mathbf{\% )}$ & Troponin-T positive $(\mathbf{n}=\mathbf{1 0 0}), \mathbf{n}(\mathbf{\%})$ & Total, $\mathbf{n}(\mathbf{\%})$ & $\mathbf{p}$ \\
\hline Deranged & $2(2.78)$ & $100(100.00)$ & $102(59.30)$ & $<0.0001$ \\
Normal & $70(97.22)$ & $0(0.00)$ & $70(40.70)$ & \\
\hline
\end{tabular}

CK MB: Creatine kinase muscle-brain

Table 5: Lactate dehydrogenase derangement

\begin{tabular}{lllll}
\hline LDH (IU/L) & Troponin-T negative (n=72), $\mathbf{n}(\%)$ & Troponin-T positive $(\mathbf{n = 1 0 0 ) , ~} \mathbf{n}(\%)$ & Total, $\mathbf{n}(\%)$ & $\mathbf{p}$ \\
\hline Deranged & $12(16.67)$ & $100(100.00)$ & $112(65.12)$ & $60(34.88)$ \\
Normal & $60(83.33)$ & $0(0.00)$ & $<0.0001$ \\
\hline
\end{tabular}

LDH: Lactate dehydrogenase

Table 6: C-reactive protein derangement

\begin{tabular}{lllll}
\hline CRP (mg/L) & Troponin-T negative ( $\mathbf{n = 7 2 ) ,} \mathbf{n}(\%)$ & Troponin-T positive $(\mathbf{n}=\mathbf{1 0 0}), \mathbf{n}(\mathbf{\%})$ & Total, $\mathbf{n}(\mathbf{\%})$ & $\mathbf{p}$ \\
\hline Deranged & $0(0.00)$ & $4(4.00)$ & $4(2.33)$ & 0.141 \\
Normal & $72(100.00)$ & $96(96.00)$ & $168(97.67)$ & \\
\hline
\end{tabular}

CRP: C-reactive protein

\section{CONCLUSION}

CK-MB and LDH are found to be sensitive cardiac markers for the diagnosis of MI and thus, a panel of markers can be used for the specific diagnosis and follow-up of AMI cases.

\section{AUTHOR CONTRIBUTIONS}

- $\quad 1^{\text {st }}$ Author- Guarantor, Data acquisition, from inception till end of study

- $2^{\text {nd }}$ Author-Concept and Design of study, Clinical study, final approval of the version

- $\quad 3^{\text {rd }}$ Author-Concept and Design of study, Clinical study, final approval of the version

- $4^{\text {th }}$ Author-Concept and Design of study, Clinical study, final approval of the version.

\section{CONFLICTS OF INTEREST}

All authors have none to declare.

\section{REFERENCES}

1. Sankeerthi C, Vaithialingam A, Rani TS, Kiran BS, Mohanalakshmi T, Prabhakar ER. Evaluation of clinical utility of serum enzymes, lipid profile, homocysteine in early stages of acute myocardial infarction. Res J Pharm Biol Chem 2014:5:755-9.

2. Roger VL. Epidemiology of myocardial infarction. Med Clin North Am 2007;91:537-52.

3. Rosamond W, Flegal K, Furie K, Go A, Greenlund K, Haase N, et al. Heart disease and stroke statistics--2008 update: A report from the American heart association statistics committee and stroke statistics subcommittee. Circulation 2008;117:e25-146.

4. Akasha R, Amanullah M, Ali SP, Sirageldin E, Elrahim MA,
Modawe G. Assessment of acute myocardial infarction by the use of special biochemical markers. Ulutas Med J 2015;1:68-73.

5. Al-Muhtaseb N, Al-Kaissi E, Muhi-Eldeen Z, Arafat T, Al-Muhtaseb S, Atiyah $\mathrm{H}$. Oxidants and antioxidants as risk factors in young Arabian male patients with acute myocardial infarction. Int J Pharm Pharm Sci 2016;8:273-7

6. Kasper DL, Fauci AS, Hauser SL, Longo DL, Jameson JL, Loscalzo J. Harrison's Principles of Internal Medicine. New York: McGraw Hill Education; 2017. p. 1593-610.

7. Gerhardt W, Katus H, Ravkilde J, Hamm C, Jørgensen PJ, Peheim E, et al. S-troponin $\mathrm{T}$ in suspected ischemic myocardial injury compared with mass and catalytic concentrations of S-creatine kinase isoenzyme MB. Clin Chem 1991;37:1405-11.

8. Gupta G, Preeti S, Kumar P, Sharma R. Cardiovascular risk in patients with mild to severe subclinical hypothyroidism. Asian J Pharm Clin Res 2016;9:1-3

9. Shah $\mathrm{H}$, Haridas N. Evaluation of clinical utility of serum enzymes and troponin- $\mathrm{T}$ in the early stages of acute myocardial infarction. Indian J Clin Biochem 2003;18:93-101.

10. Ashraf MU, Aslam M, Ajmal MR, Habib A. Relationship of serum homocysteine levels with cardiac troponin and ejection fraction in patients admitted with acute coronary syndrome. Int J Adv Pharm Med Bioallied Sci $2015 \cdot 2 \cdot 131-5$.

11. Sorathia P, Pradhan R, Lekharu R. A study of serum homocysteine levels in acute myocardial infarction patients. Int J Curr Res 2014;6:8171-3.

12. Singh SP, Manda R. A prospective observational study on risk assessment of STEMI patients at a tertiary care hospital. Int J Pharm Pharm Sci 2014;7:148-53.

13. Aseri ZA, Habib SS, Alhomida AS, Khan HA. Relationship of high sensitivity C-reactive protein with cardiac biomarkers in patients presenting with acute coronary syndrome. J Coll Physicians Surg Pak 2014;24:387-91.

14. Shah PK. Study of cardiac markers in acute myocardial infarction patients research. Indian J Pharm Biol Res 2016;4:19-22. 